\title{
Left Atrial Thromboendarterectomy in Rheumatic Mitral Valve Patients
}

\author{
Noell Fasol ${ }^{1}$, Berit BODE ${ }^{1}$, Xue LI' ${ }^{2}$, Anneli Seppälä Lindroos ${ }^{2}$ and Roland FASOL ${ }^{1 *}$ \\ ${ }^{1}$ Department of Cardiac Surgery, China \\ ${ }^{2}$ Department of Cardiology, China
}

Received: November 14, 2018; Published: January 18, 2019

*Corresponding author: Roland FASOL, MD, Department of Cardiac Surgery, Tree Top Hospital, China

\begin{abstract}
Background: Rheumatic mitral valvular heart disease is associated with the increased risk of significant left atrial enlargement and massive thrombus formation, although there are limited data on surgery and the prognosis of those patients.

Methods: We enrolled 16 patients ( $56.8 \pm 6 \mathrm{yrs}$ ) in rural China with massive thrombus formation in the enlarged left atrium ( $\varnothing 61.5 \pm 6.5 \mathrm{~mm}$ ) out of 120 consecutive patients with rheumatic mitral disease operated during a 6-month study period. Fourteen (87.5\%) had concomitant diseases: tricuspid incompetence in 12 , aortic stenosis in 3 , and coronary artery disease in 3 . The surgical technique of left atrial thromboendarterectomy included a careful blunt subendocardial dissection in order to separate 'in toto' the thick organized thrombotic material from the enlarged left atrial wall. Surgical volume reduction of the giant left atrium was performed using a circumferential atrioplasty of the posterior and inferior atrial wall. Early follow up was done after 3 months in the hospital, and after 6 and 12 months by telephone interview.
\end{abstract}

Results: There was no perioperative and early death in the 16 patients with a left atrial thromboendarterectomy and no neurological event. At one year follow up there was one confirmed postoperative death, 4 were lost to follow-up, but the remaining 11 patients describing their NYHA functional class as I and II and 3 patients even reported to be back at work.

Conclusion: Aggressive approach to left atrial thromboendarterectomy and atrioplasty for volume reduction in patients with rheumatic mitral stenosis and giant left atrium is safe, efficient and successful.

Keywords: Mitral Valve; Rheumatic Heart Disease; Left Atrium; Atrial Fibrillation

\section{Introduction}

Rheumatic heart disease (RHD) seems to have been eradicated in western countries. However, it is not in the rest of the world [1]. China has been struck by disasters, civil war and cultural revolution for the last centuries. Universities were closed, medical education stopped, and medical infrastructure was lost. As a result, we now see a high percentage of patients with rheumatic heart valve disease in newly opened heart centres. The Jilin Heart Hospital is one of the first private and non-profit heart centers in rural China. We initiated a novel social health care reimbursement model program for the Jilin Province-the JIXIN Program (Ji Jilin/吉, Xin - Heart/心)-that allows a full cost coverage for cardiac diagnosis and treatment for the rural population of the Jilin province in our hospital. This allows for the first time a real medical treatment for the rural population. Since there is hardly any modern medical infrastructure available for patients in the countryside, most of our patients have ever been exposed to any kind of substantial medical diagnosis and treatment.

There are significant socio-economic disparities in China and a massive gap between urban and rural population groups [2]. While the wealthier share of the Chinese population has benefited from advanced health technologies and spending on health care, the poor have lost access to even the most essential services. In terms of rural-urban disparity across provinces, life expectancy drops parallel to a rising share of rural population [3]. We know our patient population represents a rare group of patients, if compared to western countries were patients are normally exposed to state-of-the-art pre-operative diagnosis and treatment as well as post-operative follow-up and care.

Rheumatic heart disease is the most common cause of pathology in our patients coming for mitral valve surgery to our hospital. Atrial fibrillation enlarged left atria, severe pathological pulmonary hypertension and involvement of more than one valve is seen in most of our patients. Giant left atrium and massive thrombus formation is only seen in few. There are only several case reports $[4,5]$ but no larger series found in the literature. This study describes a 6-month experience of 16 consecutive mitral valve patients who had left atrial thromboendarterectomy (LATEA) due to massive thrombus formation in the enlarged (giant) left atrium combined with a left atrioplasty for volume reduction. 


\section{Open Access Journal of Surgery}

\section{Patients and Methods}

This investigation was exempt from a formal Institutional review board as it represents a retrospective analysis of our patient data that are collected for quality analysis and purposes other than research.

\section{Data Acquisition}

Patient records for all mitral valve operations were evaluated from the department database for the 6-month study period. Study inclusion criteria included all patients undergoing primary, isolated or combined mitral valve surgery.

\section{Patients}

Preoperative, operative and early postoperative results were assessed in 120 consecutive RHD patients who underwent intervention on the mitral valve. Of these patients, 42 (35\%)

Table 1: Patients Characteristics (all rheumatic mitral patients, $n=120$ ). underwent mitral repair, 78 (65\%) mitral replacement and 90 (75\%) had concomitant surgical procedures. Only 32 (26,6\%) patients had isolated mitral surgery. Rheumatic lesions were the cause for surgery in all 120 patients (25\%) out of 479 patients operated during this period. The presenting symptom was dyspnea at exertion and at rest. 106 patients (88.3\%) were in New York Heart Association (NYHA) functional class III and IV. Preoperative and operative patient characteristics are detailed in Table 1. In 16 (13.3\%) of all RHD mitral patients massive organized thrombi covering most of the left atrial cavity were found (Figure $1 \mathrm{~A}-\mathrm{C}$ ). Nine (56.3\%) of these 16 patients had a predominant mitral valve stenosis and 7 (43.7\%) a mixed lesion. Only 2 of the 16 patients had an isolated rheumatic mitral lesion, $14(87.5 \%)$ had concomitant diseases: tricuspid incompetence in 12 , aortic stenosis in 3 , and coronary artery disease in 3 . Some patients had more than one concomitant procedure.

\begin{tabular}{|c|c|c|c|}
\hline Preoperative variable & n (\%) & Operative Variable & n (\%) \\
\hline Age (y)(range) & $53.9 \pm 8(18-69)$ & ACC (min)(range) & $53 \pm 19(24-115)$ \\
\hline Female & $67(55.8 \%)$ & concomitant procedures & $90(75 \%)$ \\
\hline NYHA class III/IV & $106(88.3 \%)$ & tricuspid valve repair (TVR) & $52(57.8 \%)$ \\
\hline Atrial fibrillation & $89(74.2 \%)$ & aortic valve replacement (AVR) & $15(16.7 \%)$ \\
\hline Tobacco use & $79(65.8 \%)$ & AVR + TVR & $17(18.7 \%)$ \\
\hline BMI & $21.3 \pm 4.7$ & coronary artery bypass + TVR & $6(6.6 \%)$ \\
\hline
\end{tabular}

NYHA-New York Heart Association; ACC-aortic cross clamp (time/min); TVR-tricuspid valve repair; AVR-aortic valve replacement; BMI-body mass index $\left(\mathrm{kg} / \mathrm{m}^{2}\right)$.

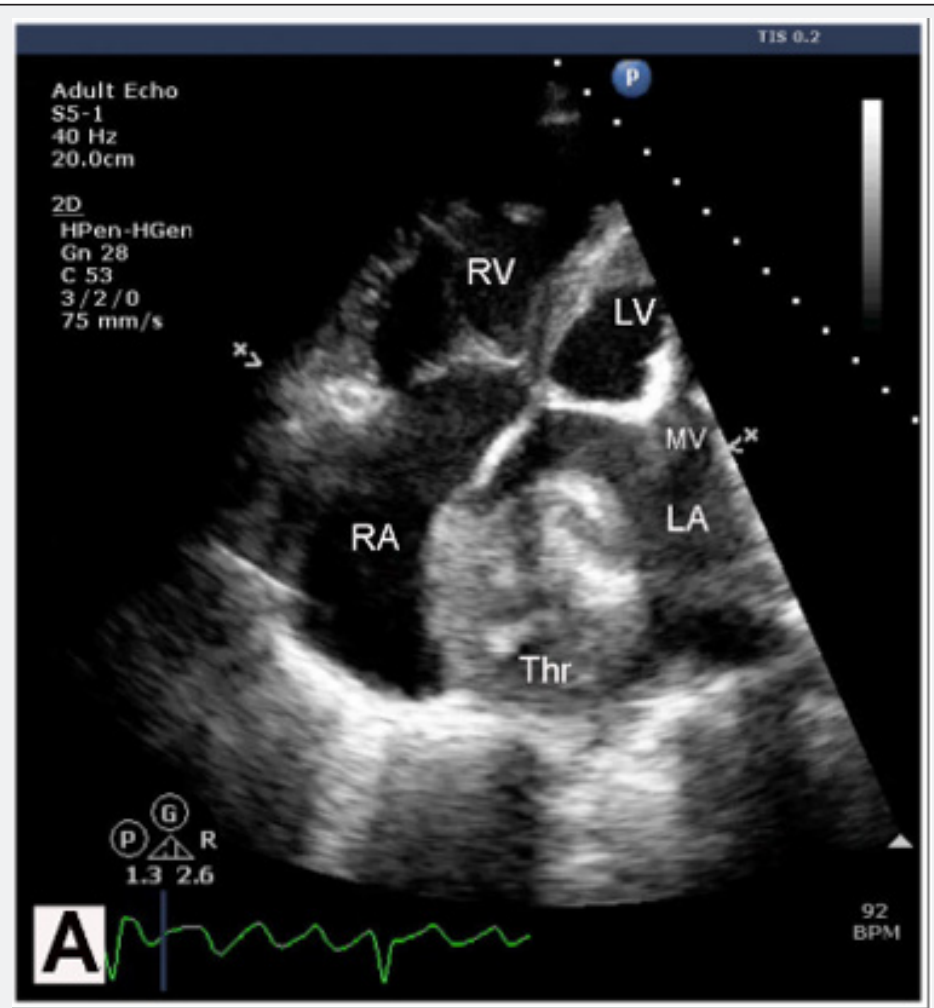

Figure 1A: Preoperative echocardiography showing a huge solid thrombus in the enlarged left atrium. [RV-right ventricle; RA-right atrium; LV-left ventricle; MV-mitral valve; LA-left atrium; Thr-thrombus]. 


\section{Open Access Journal of Surgery}

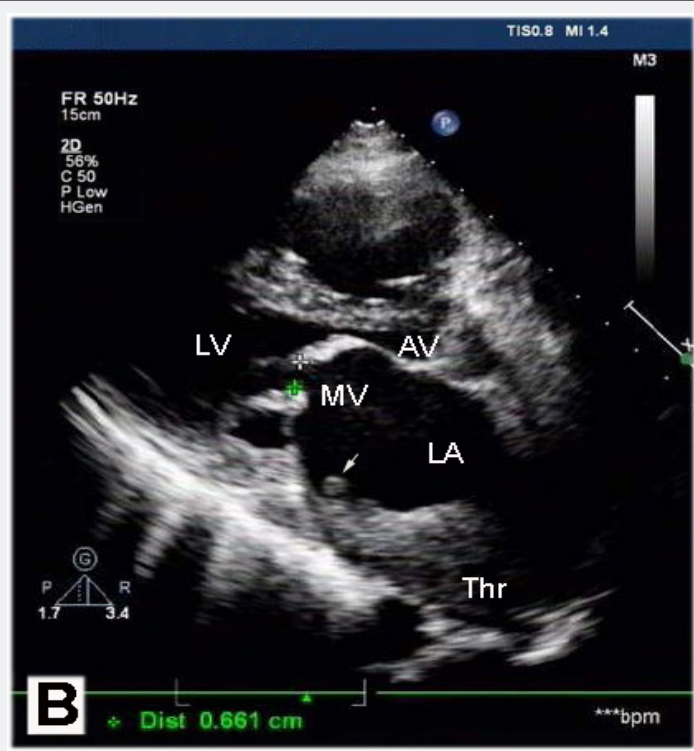

Figure 1B: Preoperative echocardiography showing a hugely enlarged (giant) left atrium with a thrombus and some floating clots (arrow) [AV-aortic valve]

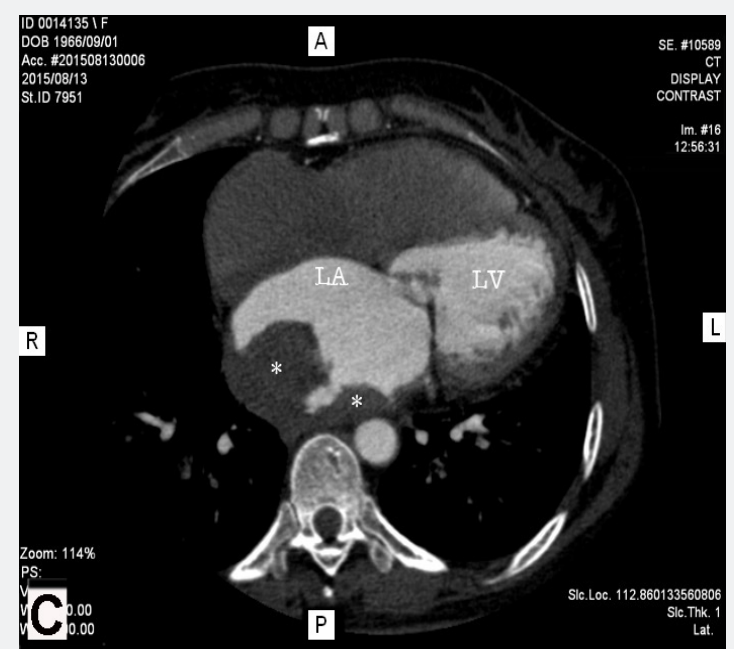

Figure 1C: Preoperative computed tomography scan showing the left atrial thrombus covering a greater part of the left atrial wall. ${ }^{*}$ left atrial thrombus].

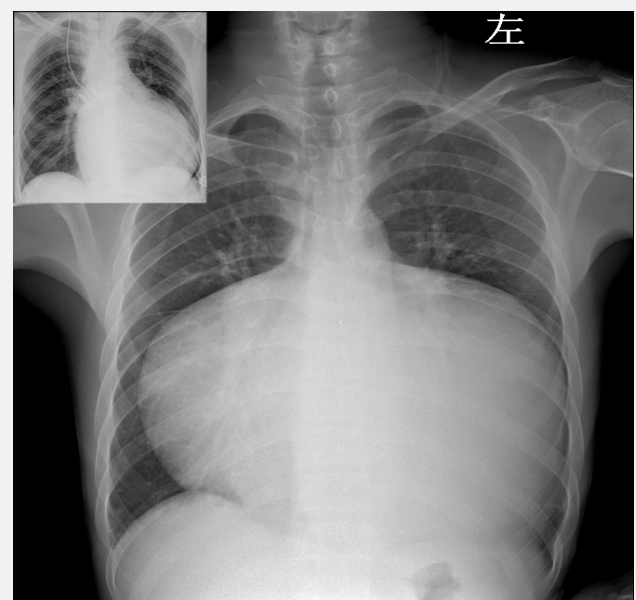

Figure 2: Preoperative chest x-ray illustrating the markedly enlarged heart and cardiothoracic ratio and (giant) left atrium of a rheumatic mitral valve patient. Note the huge left atrium shifted close to the right lateral chest wall. [inlet] Postoperative chest $\mathrm{x}$-ray of the same patient showing the remarkable effect of surgical atriotomy and volume reduction on the left atrium. 


\section{Open Access Journal of Surgery}

In these 16 mitral patients (characteristics are detailed in Table 2) a thromboendarterectomy and surgical atrioplasty for volume reduction of the giant enlarged left atrium was performed (Figures 2 \& 3). In 6 (37.5\%) of all 16 patients with left atrial thrombi some history of a possible stroke or neurological event was mentioned in their patient history. However, no detailed documentation of the event was available, and no symptoms of a neurological deficit could be observed.

Table 2: Patients Characteristics-Patients with LA-TEA $(n=16)$.

\begin{tabular}{|c|c|c|c|}
\hline Preoperative variable & n (\%) & Operative variable & n (\%) \\
\hline Age (y)(range) & $56.8 \pm 6(42-65)$ & ACC (min)(range) & $62 \pm 15(50-81)$ \\
\hline Female & $12(75 \%)$ & concomitant procedures & $14(87.5 \%)$ \\
\hline NYHA class III/IV & $16(100 \%)$ & tricuspid valve repair (TVR) & $8(57.1 \%)$ \\
\hline Atrial fibrillation & $16(100 \%)$ & aortic valve replacement (AVR) & $2(14.3 \%)$ \\
\hline History of stroke & $6(37.5 \%)$ & AVR + TVR & $1(7.1 \%)$ \\
\hline Mitral-stenosis & $9(56.3 \%)$ & coronary artery bypass + TVR & $3(21.4 \%)$ \\
\hline Mixed lesion & $7(43.7 \%)$ & & \\
\hline
\end{tabular}

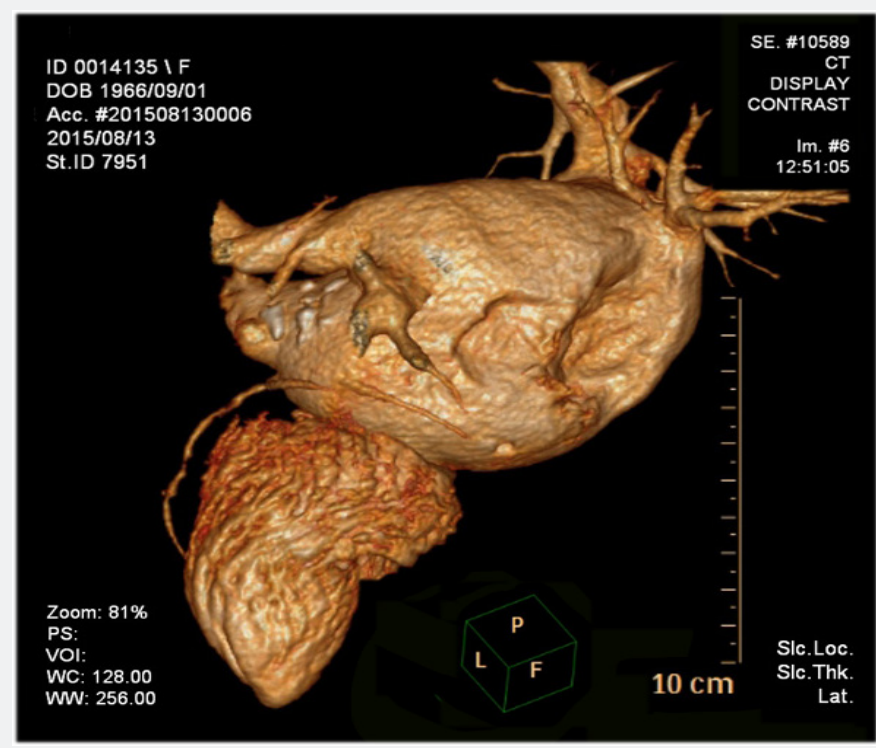

Figure 3: 3D CT image demonstrating the giant left atrium, if compared to the size of the left ventricle, of a rheumatic mitral valve patient with left atrial thrombi.

\section{Echocardiographic Studies}

Preoperative transthoracic echocardiography was performed within 5 days before surgery and routine transesophageal assessment was done intraoperatively in all patients. Postoperatively, all patients were followed echocardiographically on the first post- operative day, at the time of discharge from hospital and then 3 months afterwards. Pre- and postoperative echocardiographic variables of all 16 patients with LA-TEA are detailed in Table 3. Echocardiographic data were measured according to American Society of Echocardiography criteria [6].

Table 3: Pre- and Postoperative Echocardiographic Variables- all Patients with Left Atrial Thromboendarterectomy $(n=16)$.

\begin{tabular}{|c|c|c|c|c|}
\hline Variable & Pre OP & Post OP* & 3 Month & Normal values \\
\hline $\mathrm{EF}^{1}(\%)$ & $58.8 \pm 13$ & $61.3 \pm 12$ & $58.4 \pm 10$ & {$[3.5-5.6]$} \\
\hline LVI Dd (cm) & $4.2 \pm 0.7$ & $4.3 \pm 0.5$ & $4.3 \pm 0.6$ & {$[0.7-2.3]$} \\
\hline RV Dd (cm) & $2.4 \pm 0.4$ & $2.2 \pm 0.3$ & $2.1 \pm 0.4$ & {$[30-40]$} \\
\hline$\varnothing \mathrm{LA}(\mathrm{mm})$ & $61.5 \pm 6.5$ & $52.3 \pm 7.6$ & $49.3 \pm 7.8$ & {$[15-30]$} \\
\hline PAPs (mmHg) & $64.6 \pm 17$ & - & - & {$[4.0-6.0]$} \\
\hline MVOA (cm $\left.{ }^{2}\right)$ & $0.6 \pm 0.2$ & - & - & {$[<2.0]$} \\
\hline MVPG (mmHg) & $21.8 \pm 7.8$ & - & & {$[11$} \\
\hline
\end{tabular}

EF-ejection fraction; LVI Dd-left ventricular internal end diastolic diameter; RV Dd-right ventricular end diastolic diameter; øLA - left atrial diameter; PAPs-systolic pulmonary artery pressure; MVOA-mitral valve orifice area; MVPG-mitral valve peak gradient; * at discharge; ${ }^{1}$ Simpson. 


\section{Preoperative therapy}

There was hardly any preoperative therapy before admission to our hospital. However, substances known as "Traditional Chinese Medicine' (TCM) were taken by all of our patients. This included different kind of teas or pastilles, but also tiger bones, herbal and fungal ingredients and others like dried seahorses. Although $74.2 \%$ of all patients and $100 \%$ of the 16 patients with a LAT presented with atrial fibrillation there was no systematic preoperative anticoagulation therapy in any. Routine preoperative in-hospital therapy included 2x3.000 IU low molecular weight Heparin, diuretics, Digoxin for heart rate control, and ß-blocker as well as ACE-inhibitor medication for hypertensive patients. Ten (8.3\%) of all 120 and $3(18.7 \%)$ of the 16 LAT patients had to be recompensated prior to preoperative diagnostic echocardiography, angiogram and surgery due to severe heart failure with dyspnea at rest and problems to even lie down for the time of examination.

\section{Patient Selection}

During the 6-month study period 26 patients have been discharged from the hospital prior to surgery. The reasons were refused informed consent by the patient and his relatives in 8 , referral to other hospitals for subsequent diagnosis and treatment of suspected malignant diseases in 5, significantly pathological and therapy resistant lung function parameters in 4 cases, and 2 patients had progressive non-infective liver failure due to taking unknown (TCM) substances. In additional 7 patients' surgery was refused by the combined cardiological and surgical patient conference due to expected high perioperative risks. In consideration of ominous threads of aggression by relatives
[7], one of our cardiologists was physically attacked in the cath lab, the surgical team adapted a policy of minimizing potential perioperative complications to prevent aggression and potential physical attacks.

\section{Management of Pulmonary Artery Hypertension (PAH)}

In addition to the hospital routine anesthesia management of patients with a preoperative systolic pulmonary artery pressure of $>60 \mathrm{mmHg}$ included the control of atrial tachycardia and the administration of phosphodiesterase type- 5 inhibitor Sildenafil (Viagra ${ }^{\circledR}$ ) $25 \mathrm{mg} /$ p.o. at $20 \mathrm{hrs}, 10 \mathrm{hrs}$ and $2 \mathrm{hrs}$ before surgery. Furthermore, the introduction of a thermodilution Swan-GanzCatheter, perioperative administration of nitric oxide (NO) gas by inhalation and Milrinone lactate in combination with Norepinephrine for weaning off extracorporeal circulation was added to the protocol.

\section{Surgical Procedures}

Surgery in all patients was performed according to the hospital routine through a median sternotomy. Normothermic cardiopulmonary bypass and Calafiore warm blood cardioplegia were used for cardiac arrest [8]. One surgeon performed all the operations. A longitudinal right atriotomy and trans septal left atriotomy was the conventional approach. With a massive thrombus present, covering most of the left atrial cavity, care was taken to search for a cleavage plane to perform a blunt subendocardial dissection in order to separate 'in toto' all the thick organized thrombotic material from the left atrial wall (Figure 4). Careful handling of the thrombotic mass was mandatory to prevent intraoperative embolization.

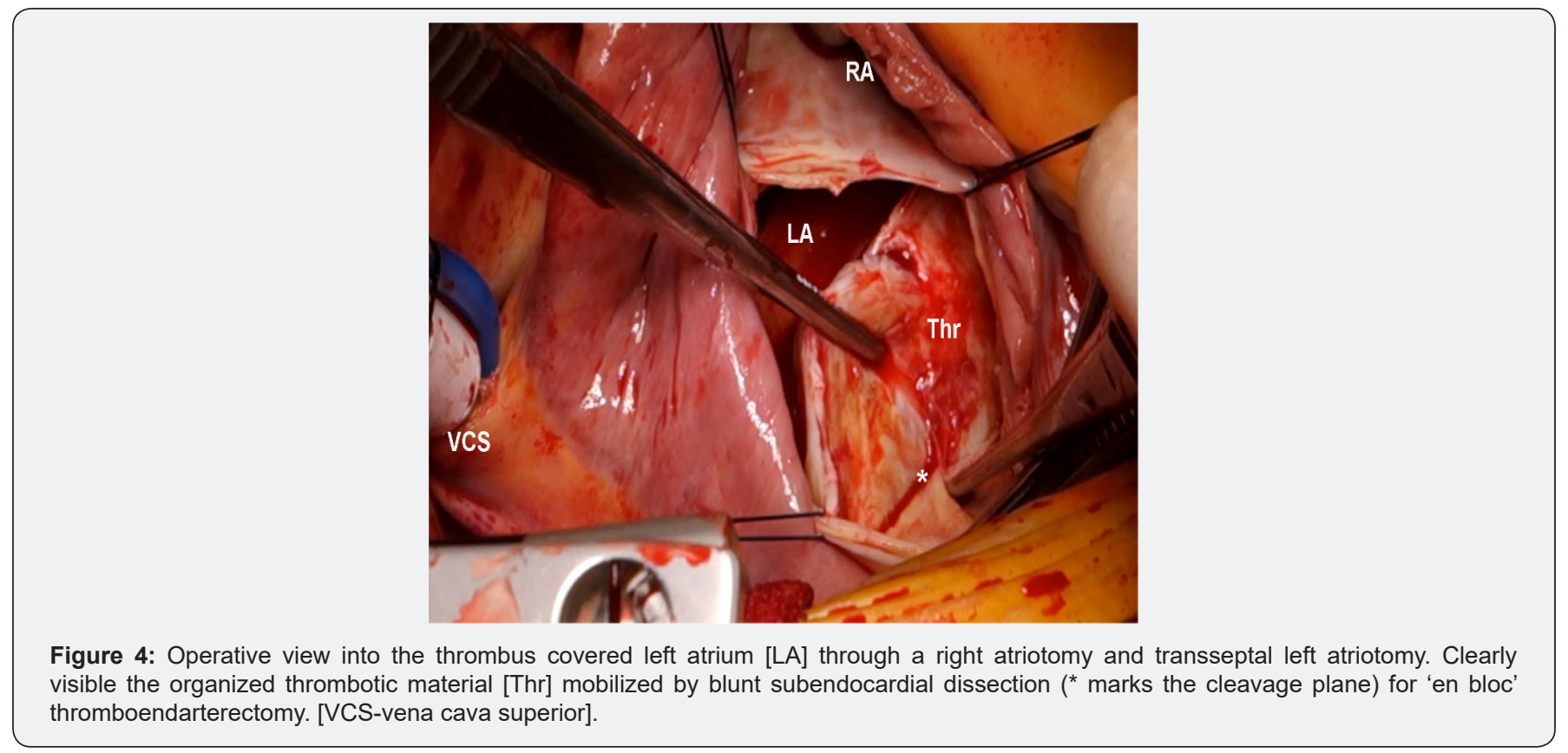

The empty left atrium was carefully and thoroughly rinsed with water and the pulmonary veins are aspirated with the sucker to remove all possible remnants of thrombotic material. In addition, a gauze was used to carefully clean the left atrial cavity. Subsequent repair of rheumatic valves was performed according to Carpentier concepts [9] and as described by Chotivatanapong [10]. Mitral valve replacement was indicated according to American College of Cardiology/American Heart Association Guidelines [11]. 


\section{Open Access Journal of Surgery}

\section{LA Atrioplasty}

Following LA-TEA and mitral repair or replacement a surgical volume reduction of the giant enlarged left atrium was performed. Starting the circumferential atrioplasty with a suture closure of the left atrial appendix, the dilated tissue of the posterior and inferior left atrial wall was plicated internally with a 5.0 Prolene suture running clockwise toward the border of the transseptal left atriotomy, posteriorly to the circumflex artery and along the posterior mitral annulus (Figure 5). Care was taken to stay clear and not involve the circumflex artery and the coronary sinus.

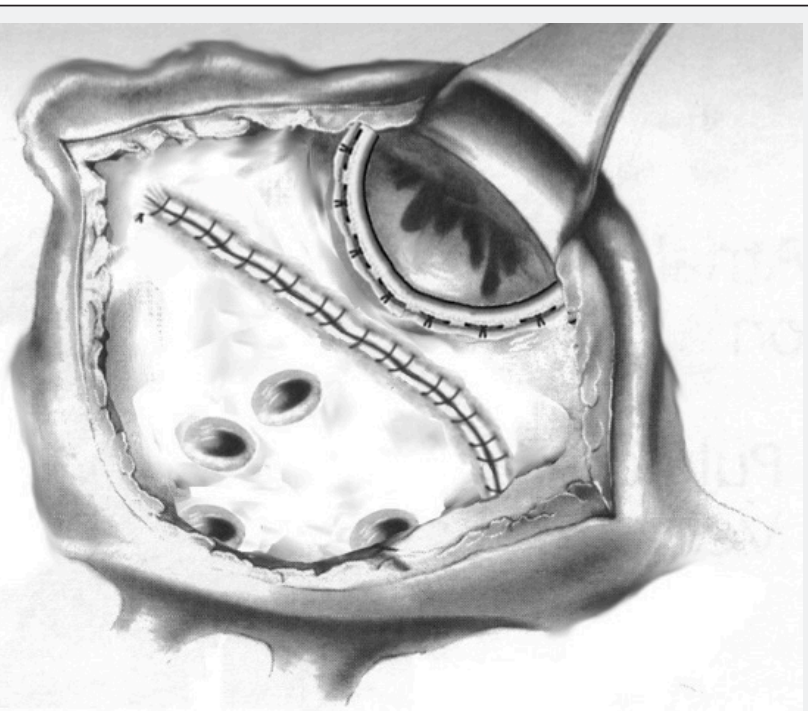

Figure 5: LA atrioplasty: schematic drawing of a view into the left atrium demonstrating the circumferential atrioplasty suture line including the left atrial appendix and plicating the dilated tissue of the posterior and inferior wall of the left atrium.

\section{Follow-up}

Patient follow-up data after discharge from the hospital were collected at 3,6\&12 months postoperatively. For the 3-month follow-up all 16 LA-TEA patients were seen at the hospital, a clinical assessment and a transthoracic echocardiography was performed. At 6 \& 12-months short term outcomes were determined by direct patient contact with a telephone interview.
At 6 month a total of 3 and at 12 months additional 2 of all 16 patients could not be contacted and were lost to follow-up.

\section{Database}

Data for all patients were recorded by the department database (Apple Macintosh and FileMaker Pro 11.0v4). Values are expressed at \pm standard deviation.

\section{Results}

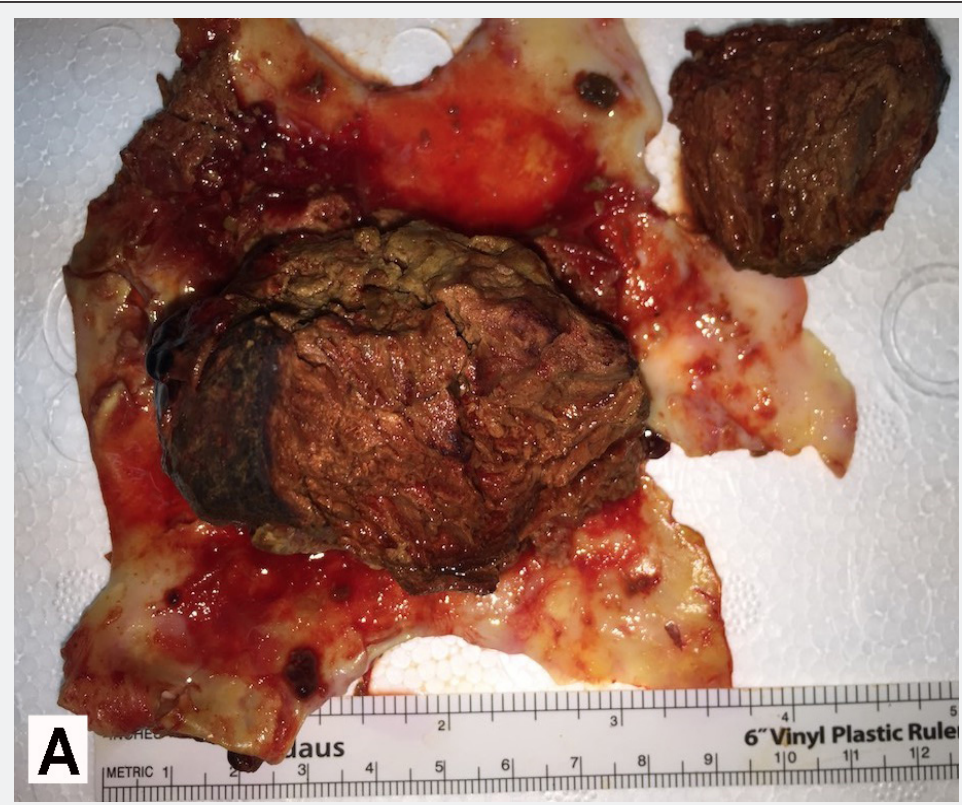

Figure 6A: Sample of a thick organized thrombotic material $(8 \times 6 \times 6 \mathrm{~cm})$ covered by organized scar tissue removed 'in toto' by left atrial thromboendarterectomy (see Figure $1 \mathrm{~A}$ for preoperative echocardiography). 


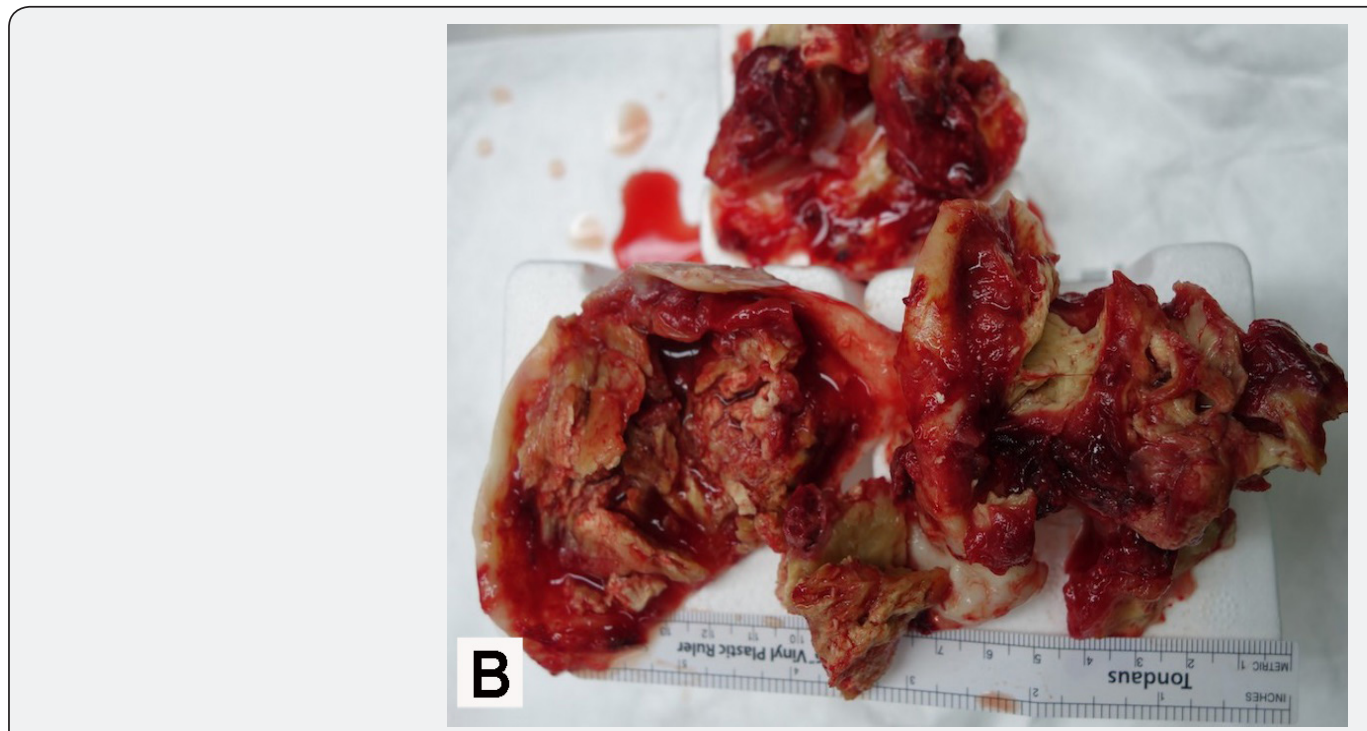

Figure 6B: A huge densely organized thrombus measuring $10 \times 7 \times 6 \mathrm{~cm}$ with additional fresh and organized clots removed 'en bloc' from the left atrium by LA-TEA.

All 16 patients with LA-TEA survived surgery uneventful without any complications. Fast track cardiac anesthesia management allowed postoperative weaning from ventilation and extubation between 2 and 6 hours postoperatively. Postoperative morbidity included 2 reoperations due to a mediastinal bleeding. There was no peri- or postoperative neurological event and there was no 30-day mortality. The surgical technique for thromboendarterectomy, to start with the search for a cleavage plane to perform a blunt subendocardial dissection to remove all thrombotic material 'en bloc' by LA-TEA, proved to be safe and effective Figure 6. It should be noted that all 16 patients with LATEA had no thrombus found in their left atrial appendix.

Preoperative blood biochemistry parameters of all 16 patients were within normal limits, except for a significantly elevated N-terminal pro B-type natriuretic peptide (NTpBNP) of $1,990 \pm 1,413 \mathrm{pg} / \mathrm{ml}$ [normal: $100-225 \mathrm{pg} / \mathrm{ml}$ ] and lactate dehydrogenase of $263 \pm 2 \mathrm{U} / \mathrm{l}$ [normal: $109-245 \mathrm{U} / \mathrm{l}$ ], total and indirect bilirubin of $29.1 \pm 9.4 \mu \mathrm{mol} / \mathrm{l}$ [normal: $2-20 \mu \mathrm{mol} / \mathrm{l}$ ] and $19.4 \pm 6.4 \mu \mathrm{mol} / \mathrm{l}$ [normal: $2-12 \mu \mathrm{mol} / \mathrm{l}$ ] as well as uric acid of $430 \pm 138 \mu \mathrm{mol} / \mathrm{l}$ [normal: $142-416 \mu \mathrm{mol} / \mathrm{l}$ ]. Preoperative coagulation system parameters were within normal limits, except a rather low fibrinogen of $2.2 \pm 0.4 \mathrm{~g} / \mathrm{l}$ [normal: $2-4 \mathrm{~g} / \mathrm{l}$ ].

Perioperative anesthesia management required substitution of fibrinogen and fresh frozen plasma due to fibrinogen levels below $1.5 \mathrm{~g} / \mathrm{l}$ and perioperative bleeding in 6 patients. Comparing blood biochemistry and coagulation system parameters of the 16 LA-TEA patients with all remaining 104 of the 120 consecutive RHD patients showed no significant differences.

All 16 patients could be discharged from the hospital between day 10 and 15. No rehabilitation facilities or professional postoperative care outside the hospital was available. All 16 could be seen at the hospital for a follow up at 3 months postoperatively. In one diabetic patient some minor local wound healing problems required treatment. Echocardiography showed normal functioning heart valves in all, but a smaller thrombus attached to the wall of the LA in one patient. In 4 a minor not, significant pericardial effusion was described and a LA function comparable to preoperative values in all patients (Table 3 ).

The size of the LA was $49.3 \pm 7.8 \mathrm{~mm}$ if compared to $61.5 \pm 6.5 \mathrm{~mm}$ preoperatively, indicative of the LA atrioplasty performed. All described their quality of life improved as compared to preoperatively, asked to choose between 'worse', 'same' and 'better'. All but 2 patients had acceptable INR values. These 2, including the one with a small LA thrombus, did not comply with their prescribed anticoagulation or other medication due to financial reasons. At 6-month postoperatively one patient was reported to have died. It was impossible to learn of any details. Two other patients could not be found and contacted for a telephone interview. The remaining 13 depicted their quality of life as 'better' and described their physical activity comparable to NYHA functional class I in 10 (76.9\%) and class II in 3 (23.1\%) patients.

At 1 year postoperatively remaining 11 patients could be contacted, including the one with a small LA thrombus. All describing their quality of life as 'better' than before, 3 reported to be back at work, and $4(36.4 \%)$ characterized their NYHA functional class as I and $7(63.6 \%)$ as class II. Two patients described themselves taking anticoagulation medicine only "sometimes ", another stopped anticoagulation due to recurrent hematoma in the leg.

\section{Comment}

Our study group represents a rare patient population that to date might not be found in the western world. In this study we enrolled 16 patients in rural China with massive thrombus formation in the giant left atrium out of 120 consecutive patients with rheumatic mitral disease. The primary findings of the study are: 
a) That these very sick patients did astonishingly well

b) That the surgical technique for 'en bloc' thromboendarterectomy proved to be safe and effective

c) That the surgical volume reduction of the giant LA with a circumferential atrioplasty was efficient and showed positive results

d) That the left atrial appendix was not the origin of LA thrombi in these 16 mitral patients

e) That these complex procedures in very sick patients showed to have good results after a short follow up of 1 year.

Rheumatic heart disease is an ongoing problem remaining endemic not only in Asia but in most of the non-western world. The total burden of cases (between 10.8 and 15.9 million in all ages) and deaths (356000 to 524000 each year) in Asia warrants attention and even suggests that the true numbers of RHD cases may be even far higher than assumed [12]. The sad story about RHD is that it could be easily controlled and prevented. It would be cheap and effective [13] and would prevent death and crippling complications as well as economic loss and avoidable costs to the underdeveloped healthcare systems [14].

However, this problem is not only neglected by media and policy makers, it is no real focus for the WHO and ignored by most other international organizations and receives only $0.1 \%$ of global research and development funding $[15,16]$. Current cardiovascular research focuses on minimal invasive approaches and new percutaneous devices. All this is important for the western world but pretty irrelevant for battling one of the top10 infectious causes of deaths in the world [17]. Surgery is a luxury not available to the poorer countries, only $11 \%$ of surgical interventions for RHD occurred in low income countries compared with $61 \%$ in high income countries [16].

There were no differences in terms of age, risk factors, valve pathology or laboratory parameters in this group of 16 patients who had LA-TEA if compared to all 120 RHD patients operated during this time. There was no parameter that could be linked to the incidence or could help to predict the risk of a LA thrombosis in this group of 16 patients, except the rheumatic mitral valve pathology. However, it was noted that in all of our Chinese patients' liver specific laboratory parameters and preoperative INR have been elevated and Fibrinogen was on the low side, but this was only a trend and not significant.

It may be assumed that specific local dietary habits including garlic, ginger, ginseng and others as well as herbal and fungal TCM substances influenced these changes in blood chemistry parameters $[18,19]$. Beside such specific local dietary habits there may be some ethnic differences in the anticoagulant activity and some genetic risk factors for the development of venous thrombosis in the Chinese population [20]. However, our laboratory was not equipped for such diagnosis. N-terminal pro B-type natriuretic peptide (NTpBNP) may be useful for diagnosing acute decompensated heart failure and was endorsed as such a test by international guidelines [21]

Furthermore, testing NTpBNP is likely to be more accurate in Asian patients [22]. On admission our 16 rural chinese patients with LA thrombus had a NTpBNP plasma level of 1,990 $\pm 1,413 \mathrm{pg} /$ $\mathrm{ml}$, considering $100-225 \mathrm{pg} / \mathrm{ml}$ as normal. However, since the group of the remaining 104 rheumatic mitral valve patients showed a level of $1,445 \pm 960 \mathrm{pg} / \mathrm{ml}$ a prevalence of significant cardiovascular disease, ventricular dilatation, atrial fibrillation or cor pulmonale, could not be identified for the group of 16 LA thrombus patients. Nevertheless, these high NTpBNP plasma levels were indicative of severe decompensated heart failure in general for all of our patients.

On admission day $77.5 \%$ of all 120 patients were in atrial fibrillation, but only 16 had left atrial thrombi, 6 of them had some history of stroke and no one had any preoperative anticoagulation or other treatment except TCM. It is often reported that the left atrial appendix is implicated as a major location for cardiac thrombus formation in patients with atrial fibrillation [23]. It seems curious, but we have not seen any thrombus formation in the left appendix in our 16 patients. However, we found left atrial thrombi involving extensive areas of the left atrium, sometimes several centimeters thick.

It is a surgical challenge to remove all this thrombotic material without leaving residual material behind and not causing atrial perforations. Leaving residual thrombotic material behind could be the future source of postoperative thromboembolic events. Undetected atrial perforation will cause immediate intraoperative bleeding complications. We found that the surgical technique of a careful blunt subendocardial dissection in order to separate in toto' the thick organized thrombotic material from the left atrial wall and to perform a left atrial thromboendarterectomy seemed to be safe and efficient. We could observe some postoperative reduced atrial dimensions but could not detect any significant hemodynamic effects. We did not experience any intra- or perioperative thromboembolism or any neurological events in this group of patients.

Previous described techniques for volume reduction of the left atrium vary from simple to do classic plication techniques involving the left atrial appendage $[24,25]$ to partial auto transplantation of the heart [26]. Our easy-to-do circumferential atrioplasty suture line including the left atrial appendix and plicating the dilated tissue of the posterior and inferior wall of the left atrium was safe and avoided extensive additional suture lines and prolonged cardiopulmonary bypass times [26].

Our group of rural chinese RHD patients was very sick, different if compared to European patients, but the prevalence of metabolic syndrome was low. The mean body mass index of our chinese patients was $21.6 \pm 3.2$, compared to $26.3 \pm 3.9$ of European heart valve patients, the percentage of smokers $65.8 \%$ compared to $37.2 \%$, and the mean age was $53.9 \pm 8$, but $65 \pm 14$ years for European valve patients [27]. $75 \%$ of our RHD patients had 
multiple-valve surgery, $18.7 \%$ of them triple valve interventions, but only $16.8 \%$ of European valve patients had multi valve surgery. Operative (30 day) mortality for all our 120 rheumatic patients was $1.7 \%$, but $6.5 \%$ for European multiple valve patients [27].

Our16RHDpatientswhohadleftatrial thromboendarterectomy, left atrial volume reduction and 14 of them concomitant valve procedures, did surprisingly well. Considering that all of them would be considered 'inoperable' in Europe, due to reduced ventricular function, right heart failure, reduced lung function and severe pulmonary artery hypertension [28]. There was no perioperative mortality and no neurological events. At one year follow up there was one confirmed postoperative death, 4 were lost to follow up, but the remaining 11 patients describing their NYHA functional class as I and II and 3 patients even reported to be back at work.

\section{References}

1. Sliwa K, Zilla P (2012) Rheumatic heart disease: the tip of the iceberg. Circulation 125(25): 3060-3062.

2. Meng Q, Zhang J, Yan F, Hoekstra EJ, Zhuo J (2012) One country, two worlds-the health disparity in China. Glob Public Health 7(2): 124-136.

3. (2016) WHO's macroeconomics and health initiative. China: Health, poverty and economic development.

4. Lim C, Rhyu WH, Lee Y, Choh JH (2005) Management of left atrial endocardium after extensive thrombectomy. Ann Thorac Surg 79(1): e11-2.

5. Darwazah AK, El Sayed H (2013) Giant left atrium associated with massive thrombus formation. Thromb J 11(1): 5.

6. Ouinones MA, Otto CM, Stoddard M, Waggoner A, Zoghbi WA, et al. (2002) Recommendations for quantification of Doppler echocardiography. A report from the Doppler quantification task force of the nomenclature and standards committee of the American Society of Echocardiography. J Am Soc Echocardiogr 15(2): 167-184.

7. Yao S, Zeng Q Peng M, Ren S, Chen G, et al. (2014) Stop violence against medical workers in China. J Thorac Dis 6(6): E141-E145.

8. Calafiore AM, Teodori G, Mezzetti A, Bosco G, Verna AM, et al. (1995) Intermittent antegrade warm blood cardioplegia. Ann Thorac Surg 59(2): 398-402.

9. Carpentier AF (1983) Cardiac valve surgery-the French correction. J Thorac Cardiovasc Surg 86(3): 323-337.

10. Chotivatanapong T, Lerdsomboon P, Sungkahapong V (2012) Rheumatic mitral valve repair: experience of 221 cases from Central Chest Institute of Thailand. J Med Assoc Thai Suppl 8: S51-57.

11. Nishimura, Catherine M Otto, Robert O Bonow, Blase A Carabello, John $\mathrm{P}$ Erwin, et al. (2014) ACC/AHA guidelines for the management of patients with valvular heart disease: a report of the American College of Cardiology/American Heart Association Task Force on Practice Guidelines. J Thorac Cardiovasc Surg 148(1): e1-e132.
12. Carapetis JR (2008) Rheumatic heart disease in Asia. Circulation 118: 2748-2753.

13. Zachariah JP, Samnaliev M (2015) Echo-based screening of rheumatic heart disease in children: a cost-effectiveness Markov model. J Med Econ 18(6): 410-419.

14. Manji RA, Witt J, Tappia PS, Jung Y, Menkis AH, et al. (2013) Costeffectiveness analysis of rheumatic heart disease prevention strategies. Expert Rev Pharmacoecon Outcomes Res 13(6): 715-724.

15. Moran M, Guzman J, Henderson K, G Finder (2012) Neglected Disease Research and Development-A Five Year Review. Sydney: Policy Cures.

16. Carapetis JR (2015) The stark reality of rheumatic heart disease. Eur Heart J 36(18): 1070-1073.

17. Carapetis JR, Steer AC, Mulholland EK, Weber M (2005) The global burden of group A streptococcal diseases. Lancet Infect Dis 5(11): 685-694.

18. McEwen BJ (2015) The influence of herbal medicine on platelet function and coagulation: a narrative review. Sem Thromb Hemost 41(3): 300-314.

19. Woodbury A, Sniecinski R (2016) Garlic-induced surgical bleeding: how much is too much? A A Case Rep 7(12): 266-269.

20. Tang L, Lu X, Yu JM, Wang QY, Yang R, et al. (2012) PROC c.574_576del polymorphism: a common genetic risk factor for venous thrombosis in the Chinese population. J Thromb Haemost 10(10): 2019-2026.

21. Roberts E, Ludman AJ, Dworzynski K, Al Mohammad A, Cowie MR, et al. (2015) The diagnostic accuracy of the natriuretic peptides in heart failure: systematic review and diagnostic meta-analysis in the acute care setting. BMJ 350: 910.

22. Ibrahim I, Kuan WS, Frampton C, Troughton R, Liew OW, et al. (2017) Superior performance of $\mathrm{N}$-terminal pro brain natriuretic peptide for diagnosis of acute decompensated heart failure in an Asian compared with a Western setting. Eur J Heart Fail 19(12): 209-2017.

23. Gillinov AM (2007) Advances in Surgical Treatment of Atrial Fibrillation. Stroke 38(2 suppl): 618-623.

24. Bourguignon T, Pressacco J, Belley Côté E, Laflamme M, El Hamamsy I (2013) Mitral annulus reconstruction and giant left atrial reduction plasty. Ann Thorac Surg 95(3): 1101-1103.

25. Adams C, Busato GM, Chu MW (2012) Left atrial reduction plasty: a novel technique. Ann Thorac Surg 93(3): 77-79.

26. Lessana A, Scorsin M, Scheublé C, Raffoul R, Rescigno G (1999) Effective reduction of a giant left atrium by partial autotransplantation. Ann Thorac Surg 67: 1164-1165.

27. Lung B, Baron G, Butchart EG, Delahaye F, Gohlke Bärwolf C, et al. (2003) A prospective survey of patients with valvular heart disease in Europe: The Euro Heart Survey on Valvular Heart Disease. Eur Heart J 24(13): 1231-1243.

28. Bilge M, Alsancak Y, Alis S, Yasar AS (2015) Concurrent transcatheter aortic valve implantation and percutaneous transvenous mitral commissurotomy for totally percutaneous treatment of combined severe rheumatic aortic and mitral stenosis. J Heart Valve Dis 24(3): 286-289. 


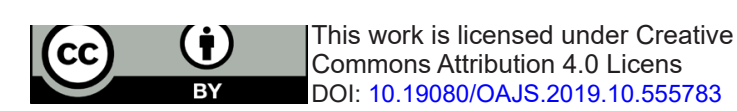

\section{Your next submission with Juniper Publishers will reach you the below assets}

- Quality Editorial service

- Swift Peer Review

- Reprints availability

- E-prints Service

- Manuscript Podcast for convenient understanding

- Global attainment for your research

- Manuscript accessibility in different formats

( Pdf, E-pub, Full Text, Audio)

- Unceasing customer service

Track the below URL for one-step submission https://juniperpublishers.com/online-submission.php 